\title{
Article \\ Comparative Investigation of Cellular Effects of Polyethylene Glycol (PEG) Derivatives
}

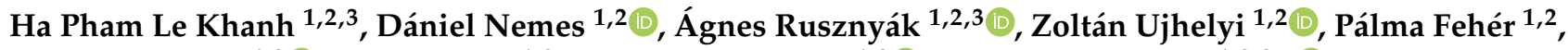 \\ Ferenc Fenyvesi ${ }^{1,2}{ }^{(0}$, Judit Váradi ${ }^{1,2}$, Miklós Vecsernyés ${ }^{1,2}$ and Ildikó Bácskay ${ }^{1,2,3, *(\mathbb{C}}$
}

1 Department of Pharmaceutical Technology, Faculty of Pharmacy, University of Debrecen, Nagyerdei Körút 98, 4032 Debrecen, Hungary; pham.le.khanh.ha@euipar.unideb.hu (H.P.L.K.);

nemes.daniel@pharm.unideb.hu (D.N.); rusznyak.agnes@pharm.unideb.hu (Á.R.); ujhelyi.zoltan@pharm.unideb.hu (Z.U.); feher.palma@pharm.unideb.hu (P.F.); fenyvesi.ferenc@pharm.unideb.hu (F.F.); varadi.judit@pharm.unideb.hu (J.V.); vecsernyes.miklos@pharm.unideb.hu (M.V.)

2 Doctorate School of Pharmaceutical Sciences, University of Debrecen, Nagyerdei Körút 98, 4032 Debrecen, Hungary

3 Institute of Healthcare Industry, University of Debrecen, Nagyerdei Körút 98, 4032 Debrecen, Hungary

* Correspondence: bacskay.ildiko@pharm.unideb.hu

check for updates

Citation: Pham Le Khanh, H.; Nemes, D.; Rusznyák, Á.; Ujhelyi, Z.; Fehér, P.; Fenyvesi, F.; Váradi, J.; Vecsernyés, M.; Bácskay, I. Comparative Investigation of Cellular Effects of Polyethylene Glycol (PEG)

Derivatives. Polymers 2022, 14, 279.

https://doi.org/10.3390/

polym 14020279

Academic Editors: Hisham

A. Alhadlaq and Nadia Lotti

Received: 8 November 2021

Accepted: 7 January 2022

Published: 11 January 2022

Publisher's Note: MDPI stays neutral with regard to jurisdictional claims in published maps and institutional affiliations.

Copyright: (c) 2022 by the authors Licensee MDPI, Basel, Switzerland. This article is an open access article distributed under the terms and conditions of the Creative Commons Attribution (CC BY) license (https:// creativecommons.org/licenses/by/ $4.0 /)$

\begin{abstract}
Nowadays, polyethylene glycols referred to as PEGs are widely used in cosmetics, consumer care products, and the pharmaceutical industry. Their advantageous properties such as chemical stability, low immunogenicity, and high tolerability explain why PEGs are applied in many fields of pharmaceutical formulations including parenteral, topical, ophthalmic, oral, and rectal preparations and also in modern drug delivery systems. Given their extensive use, they are considered a wellknown group of chemicals. However, the number of large-scale comparative studies involving multiple PEGs of wide molecular weight range is low, as in most cases biological effects are estimated upon molecular weight. The aim of this publication was to study the action of PEGs on Caco-2 cells and G. mellonella larvae and to calculate the correlation of these effects with molecular weight and osmolality. Eleven PEGs of different molecular weight were used in our experiments: PEG 200, PEG 300, PEG 400, PEG 600, PEG 1000, PEG 1500, PEG 4000, PEG 8000, PEG 10,000, 12,000, and PEG 20,000. The investigated cellular effects included cytotoxicity (MTT and Neutral Red assays, flow cytometry with propidium iodide and annexin V) and autophagy. The osmolality of different molecular weight PEGs with various concentrations was measured by a vapor pressure osmometer OSMOMAT 070 and G. mellonella larvae were injected with the solutions of PEGs. Sorbitol was used as controls of the same osmolality. Statistical correlation was calculated to describe the average molecular weight dependence of the different measured effects. Osmolality, the cytotoxicity assays, flow cytometry data, and larvae mortality had significant correlation with the structure of the PEGs, while autophagosome formation and the proportion of early apoptotic cells showed no statistical correlation. Overall, it must be noted that PEGs must be tested individually for biological effects as not all effects can be estimated by the average molecular weight.
\end{abstract}

Keywords: Caco-2; MTT assay; NR assay; autophagy; flow cytometry; osmolality; G. mellonella

\section{Introduction}

Polyethylene glycol (PEG) polymers are an important group of excipients due to their widespread use in different pharmaceutical formulations. PEG refers to oligomers of polyethylene oxide with different molecular weight (MW) and they are commercially available in a wide range of MW from 200 to 10,000,000 g/mol [1,2]. Physical states are varied from the clear non-volatile liquid at room temperature (low molecular weight PEG: 200-700), through semisolid (pasty material, medium MW PEG: 800-2000), to solid (white waxy solid/flakes form/powder high MW: 3000 and above) [2,3]. 
PEGs earn their fame due to their non-immunogenicity, hydrophilicity, and good solubility improving capacity [3]. The terminal hydroxyl and ether groups contribute to the high polarity characteristic of PEGs [2,3]. The low molecular weight PEGs have more hydroxyl groups compared to their structure; thus, as the molecular weight of the PEGs increases, their solubility in water and other solvents decreases [2]. Moreover, PEGs can also be dissolved in many other solvents such as tetrahydrofuran, chloroform, dimethyl sulfoxide, and methanol [4]. Under normal conditions, PEGs can be considered relatively stable; the chemical and physical changes are limited and few. However, the interaction of PEGs with given compounds might induce precipitation such as phenol, cresol, resorcinol, and tannin, hence PEGs can be used as the antidote for removing certain toxic substances [5]

On their own, PEGs are widely applied as laxatives or in preparation for surgery or colonoscopy. Due to their ability to be miscible with aqueous fluids, PEGs are used as solubilizers and permeation enhancers for many poorly soluble and low permeability compounds (BCS class II, IV) thus significantly improving the bioavailability of the given drug. It was shown that the solubility of Diazepam and Temazepam was increased by 3.5-fold and 2.5-fold, respectively, at $30{ }^{\circ} \mathrm{C}$ in water [3]. An example of permeability improvement is that the Digoxin (BCS class IV) was shown to be absorbed much better in gastrointestinal tract when formulated in a PEG 400 solution encapsulated in soft gels (Lanoxincaps ${ }^{\circledR}$ ) compared to a tablet dosage form $\left(\right.$ Lanoxin $^{\circledR}$ ) [2]. Moreover, some PEGs and its derivatives are also applied as penetration enhancers in topical dermatological preparations or cosmetics as surfactants, humectants, and emulsifiers [6]. PEG is often chosen to coat the particles surfaces of the specialized carriers used in targeted drug delivery system [7]. Due to the neutral, hydrophilic, and flexible features, these polymers form a surface layer on the nanoparticles for formulating stealth nanocarriers in cancer therapy. Thus, opsonin adhesion is reduced and the systemic circulation is prolonged by evading uptake by the reticuloendothelial system [3,8]. Doxorubicin, Taxol, and Camptothecin are typical examples of this PEGylation technique [3].

Despite their numerous advantages, several publications are available about the possible harmful effects of PEGs. Elevated serum osmolality, hypercalcemia, and renal failure were observed in an animal experiment in which New Zealand white rabbits with open wounds were treated topically with a PEG-based antimicrobial cream [9]. In a study involving Cynomolgus monkeys (Macaca fascicularis), pathological lesions in the kidney were observed at an oral dose of 2.2 to $4.4 \mathrm{~g} / \mathrm{kg}$ PEG 200, during a 13-week treatment. Intratubular deposition of oxalate crystals were detected in the renal cortex [10]. Besides animal studies, there is also some evidence for PEG toxicity in humans. Three burned patients died following a treatment with a PEG-based burn cream (the cream contained 63\% PEG 300, 5\% PEG 1000, 32\% PEG 4000, and approximately $0.01 \%$ of ethylene glycol) [11]. The autopsy of the patients revealed tubular necrosis which affected the proximal tube. Metabolic acidosis increased the serum calcium level and renal osmotic pressure. In summary, the main adverse effects of PEGs included metabolic acidosis, the increase in serum calcium, renal failure, and cytotoxicity [2,9-11].

In another study, PEG 4000, PEG 6000, and PEG 10,000 showed no cytotoxic effect on Caco- 2 cells, while PEG 400 and PEG 15,000 at $4 w / v \%$ exhibited significant toxicity on cells [12]. Parnaud et al. investigated the cytotoxicity of PEG 8000 on human adenocarcinoma HT29 and COLO 205 cells, the human foetal mucosa FHC cells and Caco-2 cells [13]. Their results showed that PEG 8000 was not significantly toxic on Caco-2 and FHC cells, but it severely inhibited the proliferation of HT29 and COLO205 cells. They suggested that PEG 8000 might own a selectively cytostatic effect on proliferating cancer cells due to its high osmotic effect.

We aimed to study the correlation between cell viability, autophagosome formation, in vivo toxicity, and the molecular weight. As most studies involved only a limited number of derivatives, and we wished to better understand the cytotoxicity of these compounds, we investigated eleven substances of various molecular weights on a much wider scale: 
PEG 200, PEG 300, PEG 400, PEG 600, PEG 1000, PEG 1500, PEG 4000, PEG 8000, PEG 10,000, PEG 12,000, and PEG 20,000.

\section{Materials and Methods}

\subsection{Materials and Sample Preparation}

A total of 12 polyethylene glycols derivatives were chosen to be investigated based on their average molecular weight. Range of molecular weight is also indicated. PEG 200 (190-210 MW), PEG 300 (290-305 MW), and PEG 600 (550-650 MW) were obtained from TCI (Zwijndrecht, Belgium). PEG 1000 (950-1050 MW), PEG 8000 (7000-9000 MW), PEG 10,000 (9000-11,250 MW), PEG 12,000 (11,000-13,000 MW), and PEG 20,000 (16,000-24,000 MW) were purchased from Alfa Aesar (Karlsruhe, Germany). PEG 400 (380-420 MW), PEG 1500 (1400-1600 MW), PEG 4000 (3500-4500 MW), and sorbitol were obtained from Molar Chemicals (Halásztelek, Hungary). All the PEGs were stored under dry and cool conditions.

The 3-(4,5-dimethylthiazol-2-yl)-2,5-diphenyltetrazolium bromide (MTT), sodium chloride, Dulbecco's Modified Eagle's Medium (DMEM), phosphate-buffered saline (PBS), trypsin from porcine, EDTA, heat-inactivated foetal bovine serum (FBS), and propidium iodide solution were purchased from Sigma-Aldrich (Budapest, Hungary). Lonza (Basel, Switzerland) provided the non-essential amino acid solution and penicillin-streptomycin mix. GlutaMax ${ }^{\mathrm{TM}}$ supplement and Annexin V Alexa Fluor ${ }^{\mathrm{TM}} 647$ conjugate were purchased from Thermo Fisher (Budapest, Hungary). Alfa Aesar (Karlsruhe, Germany) product was the Neutral Red (3-amino-7-dimethylamino-2-methylphenazine hydrochloride). Enzo Life Sciences (Farmingdale, NY, USA) provided the CYTO-ID Autophagy Detection Kit.

The PEGs with different molecular weights were all measured. PEGs were dissolved in PBS at $30 w / v \%$ concentration and these solutions were used for all experiments. All of the PEG test solutions were freshly prepared immediately before any given experiment. Different sorbitol solutions were also dissolved with PBS and freshly prepared.

\subsection{Cell Culture Maintenance}

The Caco-2 cell line were purchased from the European Collection of Cell Cultures (Salisbury, United Kingdom-catalogue No. 8601020). Cells were cultured in Nunc ${ }^{\mathrm{TM}}$ EasyFlask $^{\mathrm{TM}}$ cell culture flasks (Thermo Fisher, Darmstadt, Germany) in DMEM (containing: $0.584 \mathrm{~g} / \mathrm{L}$ L-glutamine and $4.5 \mathrm{~g} / \mathrm{L}$ D-glucose), supplemented with 10\% (v/v) FBS, $3.7 \mathrm{~g} / \mathrm{L}$ sodium hydrogencarbonate, $1 \%(v / v)$ non-essential amino acid solution, and $100 \mathrm{IU} / \mathrm{mL}$ penicillin $\mathrm{K}$, with $100 \mu \mathrm{g} / \mathrm{mL}$ streptomycin sulfate at $37^{\circ} \mathrm{C}$ in an atmosphere of $5 \% \mathrm{CO}_{2}$. Passaging was regularly performed for cell maintenance and fresh glutamine was continuously supplemented by GlutaMax ${ }^{\mathrm{TM}}$. Our experiments were carried out on cultures between passage numbers 25-40 [14].

\subsection{Cytotoxicity Assays}

The cytotoxic effects of all PEG and sorbitol solutions were measured by MTT and Neutral Red (NR) assays. Caco-2 cells with media were seeded into 96-wells plates (VWR International Inc., Debrecen, Hungary) at a density of $1 \times 10^{4}$ cells/well. After 7 days, the medium was removed, and the cells were treated with $100 \mu \mathrm{L}$ of the test solutions for $30 \mathrm{~min}$ at $37^{\circ} \mathrm{C}$. Concentrations of the test solutions were $30 w / v \%$ for all the PEG solutions and 7-10-12.5-35 $w / v \%$ for the sorbitol solutions. During the preliminary studies, lower concentrations of PEG solutions were also tested, but cytotoxicity did not exceed $20 \%$. In case of MTT assay, the test solutions were removed and a $0.5 \mathrm{mg} / \mathrm{mL}$ MTT solution (PBS as a solvent) was added to each well. The plate was again incubated for $3 \mathrm{~h}$ at $37^{\circ} \mathrm{C}$. In case of Neutral Red assay, a $16.6 \mathrm{mg} / \mathrm{mL}$ NR solution (cell culture medium as a solvent) was added to each well after removing all test solutions. The plate was incubated for $2 \mathrm{~h}$ in this case. After incubation time, all dyes were completely removed and $0.1 \mathrm{~mL}$ of an isopropanol-1 M hydrochloride acid (25:1) solution was added to each well to dissolve the cells and solubilize the formazan crystals and the incorporated Neutral Red. The absorbance of the wells was measured at $565 \mathrm{~nm}$ for MTT assay and $540 \mathrm{~nm}$ for NR assay. We used 
empty wells of the plate as a background and all the measurements were carried out with a Thermo-Fisher Multiskan Go (Thermo-Fisher, Waltham, MA, USA) microplate reader. Cell viability was expressed as a percent of the cell viability of the untreated control cells, which were incubated with PBS for $30 \mathrm{~min}$ in case of both methods [14].

\subsection{Osmolality Measurement}

The OSMOMAT 070 vapor pressure osmometer (Gonotec $\mathrm{GmbH}$, Berlin, Germany) is suitable for directly determining the total osmolality of aqueous solutions. The measurement temperature was $45^{\circ} \mathrm{C}$ and the sampling time was $5 \mathrm{~min}$. The solvent chosen was ultrapure (Type 1) water obtained from a Millipore Direct-Q 5 UV system (Millipore SAS, Molsheim, France). Before each experiment, the baseline was determined by ultrapure water. After the baseline was stable, the calibration was carried out with a $1 w / v \%$ sodium chloride solution. After the cell constant was calculated and the system calibrated with it, the PEG and sorbitol samples with increasing concentration were measured sequentially. All liquids were dropped upon the sensors twice and the second drop was used for measurement. Concentrations of the test solutions were $30 w / v \%$ for all the PEG solutions and 7-10-12.5-35 $w / v \%$ for the sorbitol solutions. The osmolality of the samples was expressed in $\mathrm{mOsmol} / \mathrm{kg}$, as an average of 4 individual measurements.

\subsection{Flow Cytometry Analysis}

A Guava ${ }^{\circledR}$ easyCyte ${ }^{\text {TM }} 5 \mathrm{HT}$ (Luminex, Austin, TX, USA) flow cytometer was used for our experiments; $3 \times 6.5$ million Caco- 2 cells were collected from cell culture flasks with a trypsin-EDTA solution and redistributed into separate tubes and 1 million cells were treated with $1 \mathrm{~mL}$ of PEG test solutions dissolved in PBS. Concentration of the test solutions was $30 w / v \%$ for all the PEG solutions. After $30 \mathrm{~min}$, the cells were centrifuged, the test solutions were removed, and the cells were gently washed with cold PBS and centrifuged again. Supernatant was removed and with annexin-binding puffer a 1 million cells $/ \mathrm{mL}$ cell suspension was created. Then, $100 \mu \mathrm{L}$ of these suspensions were treated with $5 \mu \mathrm{L}$ of Alexa Fluor ${ }^{\mathrm{TM}} 647$ and $1 \mu \mathrm{L}$ of $100 \mu \mathrm{g} / \mathrm{mL}$ propidium iodide solution. The cell suspensions were stained for $15 \mathrm{~min}$ on ice and then distributed on a 96-well microplate (3 wells/group) and analyzed. The propidium iodide was excited with a $488 \mathrm{~nm}$ laser and detected at the 525/30 $\mathrm{nm}$ channel (green parameter). The Alexa Fluor ${ }^{\mathrm{TM}} 647$ was excited with the same laser line and detected at the 695/50 nm channel (red parameter). On the FSC-SSC scatterplot the non-cellular events were excluded. On the FSC-A-FSC-W scatterplot the duplets were excluded. The remaining events $(8000-10,000)$ were analyzed on a propidium iodide-Alexa Fluor 647 scatterplot, the quadrant gates were determined on non-labelled samples. The double positive cells were regarded as necrotic/late apoptotic cells. The annexin $\mathrm{V}$ positive population was regarded as early apoptotic, the double negative population regarded as viable cells [14].

\subsection{Autophagy Assay}

The quantitative measurement of autophagosomes was carried out the CYTO-ID Autophagy Detection Kit (Enzo Life Sciences, Farmingdale, NY, USA) which is based on the staining autophagosomes. Caco-2 cells in the density of 10,000 cells/well were seeded into black 96-well plates (Greiner Bio-One, Mosonmagyaróvár, Hungary). When cells reached the appropriate confluence on the microplates (4 days), they were incubated for $30 \mathrm{~min}$ with $100 \mu \mathrm{L}$ of the PEG and sorbitol test solutions at $37{ }^{\circ} \mathrm{C}$. Concentrations of the test solutions were $30 w / v \%$ for all the PEG solutions and 7-10-12.5-35 w/v\% for the sorbitol solutions. After the treatment, wells were washed once with PBS. Cells were incubated with $1 \mathrm{~mL}$ of the given buffer which was supplemented with $1 \mu \mathrm{L}$ CYTO-ID ${ }^{\circledR}$ Green Detection Reagent and $1 \mu \mathrm{L}$ Hoechst 33,342 Nuclear Stain for $30 \mathrm{~min}$ at $37^{\circ} \mathrm{C}$. After another washing with PBS, green fluorescence intensities of the samples were measured with FLUOstar Optima microplate reader (BMG Labtech, Offenburg, Germany) at $485 \mathrm{~nm}$ excitation and $520 \mathrm{~nm}$ emission wavelengths. Hoechst 33,342 Nuclear Stain was measured at $365 \mathrm{~nm}$ 
excitation and 445 emission wavelengths. According to the manufacturer's specification, green fluorescence values were normalized to the blue fluorescence values [15].

\subsection{G. mellonella Larvae Survivability Tests}

Bugs World Inc. (Budapest, Hungary) provided the larvae of the sixth developmental stage of G. mellonella. Before the treatment, all larvae were kept at $10^{\circ} \mathrm{C}$ and in a dark environment. Specimens with length between 2 and $3 \mathrm{~cm}$ and lacking any sign of melanisation were placed in sterile vented Petri dishes. Next, $20 \mu \mathrm{L}$ of the test solutions were injected into the specimens around their last pro-leg with a $29 \mathrm{G}$ needle. Concentration of the test solutions was $30 w / v \%$ for all the PEG solutions. After treatment, the larvae were kept at $30{ }^{\circ} \mathrm{C}$ for $48 \mathrm{~h}$ shielded from light. Viability was regularly checked by gentle probing with a blunt-ended needle. If no movement was detected after the probing, the given larva was considered to be dead. Viability was observed at 19 h, 24 h, 43 h, and 48 h [14].

\subsection{Statistical Analysis}

Statistical data analysis and plotting were carried out with GraphPad Prism software (version 8; GraphPad Software, San Diego, CA, USA). All data were presented as means \pm SEM. In case of the cell viability assays, each column represents the mean of ten independent, parallelly treated wells. PEGs and sorbitol treated cells' absorbance values were compared with their given control group as they were measured on multiple microplates. Gaussian distribution was analysed with Shapiro-Wilk test and equal variances with Bartlett's test. If the data set passed both tests, a one-way ANOVA was calculated, if Bartlett's test failed, a Welsch's ANOVA was calculated, and if Gaussian distribution was not proven, then a Kruskal-Wallis test was carried out. As a post test, Dunnett's test was used to compare the treated cells' results to the controls. In each case we used significance level $p<0.05$. Significance is labelled as ns $=p \geq 0.05 ;^{*}=p<0.05 ;{ }^{* *}=p<0.01$; $* * *=p<0.001$; and ${ }^{* * * *}=p<0.0001$. In vivo survival curves of G. mellonella larvae were plotted on Kaplan-Meier curves and the different groups' survival was compared with Mantel-Cox log-rank test and Gehan-Breslow-Wilcoxon test. Osmolality, autophagy, and flow cytometry results were not analysed due to low number of parallel experiments ( $n=4$, $\mathrm{n}=4$, and $\mathrm{n}=3$, respectively). Due to this, we used Spearman correlation to calculate the relationship between molecular weight and other measured data $(p<0.05$, two-tailed).

\section{Results}

\subsection{Osmolality Results}

At first, the osmolality of PEGs was defined at $30 w / v \%$. Based upon our preliminary research, the cytotoxicity of PEGs was negligible (cell viability was above $80 \%$ for all derivatives) at concentrations below $30 w / v \%$. In order to let all derivatives exhibit their full effect on cells and in vivo specimens, further increase in concentration was needed. Sorbitol solutions were also tested in order to distinguish which biological properties are affected by osmolality and which are not. Figure 1 shows that osmolality drastically decreased from PEG 200 until PEG 4000. From this derivative, the values minimally increased until PEG 10,000 and above when values were similar.

\subsection{Cytotoxicity Assay Results}

Figure 2 shows that sorbitol solutions did not decrease the cell viability of treated Caco-2 cells according to the MTT assay. However, low molecular weight PEGs such as PEG 200, 300, and 400 severely reduced surviving cells. The other derivatives had less impact on cell viability, yet none of them had higher values than $85 \%$ and the results varied greatly regardless of molecular weight.

Neutral Red assay, as seen in Figure 3, revealed nearly identical trends compared to the MTT assay. The sorbitol solutions had no cytotoxic effects. Low molecular weight PEGs had higher impact on cell viability, however the difference between high and low molecular 
weight derivatives is smaller. The results of high molecular weight derivatives also had severe deviation.

\section{Osmolality of PEGs}

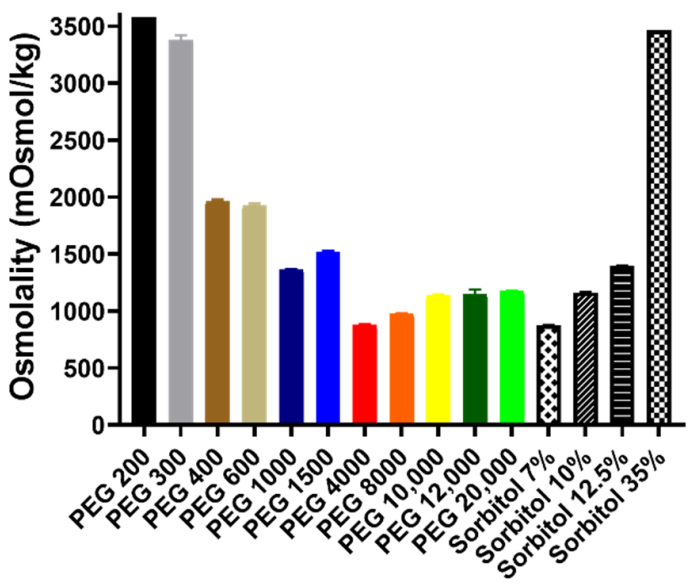

Figure 1. Osmolality of PEG and sorbitol solutions measured by vapor pressure osmometer OSMOMAT 070. Concentrations of all PEG solutions were $30 w / v \%$ and volumes were 1 drop of the solutions each time. Columns represent the mean, $\pm \mathrm{SEM}, \mathrm{n}=4$. Osmolality of the samples in mOsmol/kg (mean \pm SEM): PEG 200: $3574 \pm$ 0; PEG 300: $3381 \pm$ 38; PEG 400: $1963 \pm$ 17; PEG 600: $1926 \pm$ 17; PEG 1000: $1363 \pm$ 4; PEG 1500: $1515 \pm$ 11; PEG 4000: $877 \pm$ 9; PEG 8000: $977 \pm 3$; PEG 10,000: $1140 \pm$ 4; PEG 12,000: $1151 \pm 38$; PEG 20,000: $1174 \pm$ 5; Sorbitol $7 w / v \%: 876 \pm 2$; Sorbitol $10 w / v \%: 1164 \pm 1$; Sorbitol $12.5 w / v \%: 1395 \pm 4$; and Sorbitol $35 w / v \%: 3464 \pm 0$.

\section{MTT assay of PEGs}

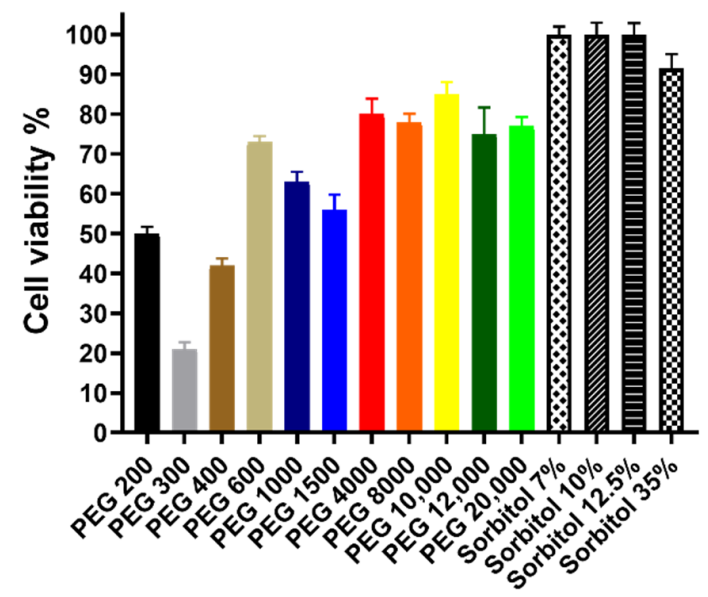

Figure 2. Cytotoxicity of PEG and sorbitol solutions measured by MTT assay on Caco-2 cells. Concentrations of all PEG solutions were $30 w / v \%$ and volumes were $100 \mu \mathrm{L}$. Cell viability expressed as the percentage of the absorbance of the untreated control cells. Columns represent the mean, \pm SEM, $\mathrm{n}=10$. Cell viability of the samples (mean \pm SEM): PEG 200: 50\% $\pm 2 \%$; PEG 300: $21 \% \pm 2 \%$; PEG 400: 42\% $\pm 2 \%$; PEG 600: 73\% $\pm 2 \%$; PEG 1000: 63\% $\pm 3 \%$; PEG 1500: $56 \% \pm 4 \%$; PEG 4000: $80 \% \pm 4 \%$; PEG 8000: 78\% \pm 2\%; PEG 10,000: 85\% $\pm 3 \%$; PEG 12,000: 75\% \pm 7\%; PEG 20,000: $77 \% \pm 2 \%$; Sorbitol $7 w / v \%: 100 \% \pm 2 \%$; Sorbitol $10 w / v \%: 100 \% \pm 3 \%$; Sorbitol $12.5 w / v \%: 100 \% \pm 3 \%$; and Sorbitol $35 w / v \%: 92 \% \pm 3.6 \%$; Levels of significance after statistical analysis treated cells compared against their respective untreated control group: PEG 200: ***; PEG 300: ***; PEG 400: ****; PEG 600: ****; PEG 1000: ****; PEG 1500: ****; PEG 4000: *; PEG 8000: ****; PEG 10,000: **; PEG 12,000: *; PEG 20,000: ****; Sorbitol $7 w / v \%$ : ns; Sorbitol $10 w / v \%$ : ns; Sorbitol $12.5 w / v \%$ : ns; and Sorbitol $35 w / v \%$ : ns. 


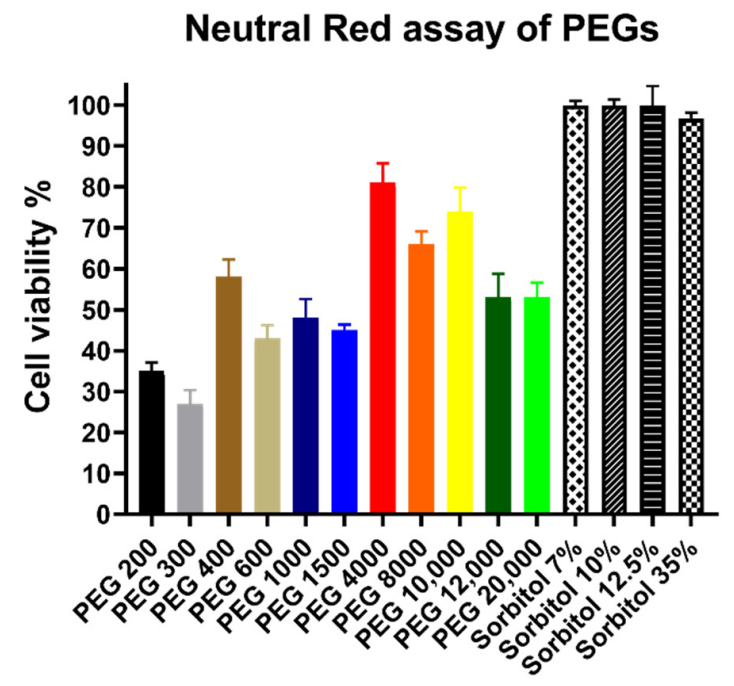

Figure 3. Cytotoxicity of PEG and sorbitol solutions measured by NR assay on Caco-2 cells. Concentrations of all PEG solutions were $30 \mathrm{w} / \mathrm{\%} \%$ and volumes were $100 \mu \mathrm{L}$. Cell viability expressed as the percentage of the absorbance of the untreated control cells. Columns represent the mean, \pm SEM, $\mathrm{n}=10$. Cell viability of the samples (mean \pm SEM): PEG 200: 35\% $\pm 2 \%$; PEG 300: 27\% $\pm 3 \%$; PEG 400: 58\% \pm 4\%; PEG 600: 43\% \pm 3\%; PEG 1000: $48 \% \pm 5 \%$; PEG 1500: $45 \% \pm 1 \%$; PEG 4000: $81 \% \pm 5 \%$; PEG 8000: 66 $\% \pm 3 \%$; PEG 10,000: 74\% \pm 6\%; PEG 12,000: 53\% \pm 6\%; PEG 20,000: 53\% $\pm 4 \%$; Sorbitol $7 w / v \%: 100 \% \pm 1 \%$; Sorbitol $10 w / v \%: 100 \% \pm 1 \%$; Sorbitol $12.5 w / v \%: 100 \% \pm 5 \%$; and Sorbitol $35 \mathrm{w} / \mathrm{v} \%: 97 \% \pm 1 \%$; Levels of significance after statistical analysis treated cells compared against their respective untreated control group: PEG 200: ***; PEG 300: ****; PEG 400: ****; PEG 600: ****; PEG 1000: ****; PEG 1500: ****; PEG 4000: **; PEG 8000: ns; PEG 10,000: ns; PEG 12,000: **; PEG 20,000: ****; Sorbitol $7 w / v \%$ : ns; Sorbitol $10 w / v \%$ : ns; Sorbitol $12.5 w / v \%$ : ns; and Sorbitol $35 w / v \%$ : ns.

\subsection{Autophagy Assay Results}

Nearly all treatments increased the number of autophagosomes, as can be seen on Figure 4. From PEG 200 to PEG 1500, there was a decreasing trend of fluorescence intensity which changed after PEG 1500 and started increasing again. Sorbitol solutions had nearly similar results than their PEG counterparts with the exception of $12.5 w / v \%$, which had higher results than PEG 1000. PEG 200 had a drastically higher intensity than any other treatment as the rest of the chemicals had their results in the range of $\sim 180 \%$ to $100 \%$.

\section{Effects of PEGs on autophagy}

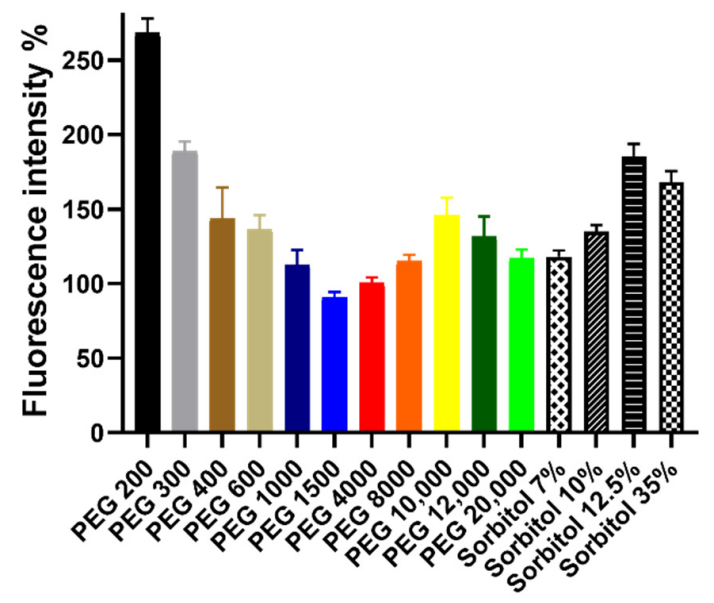

Figure 4. Effect of PEG and sorbitol solutions on the number of autophagosomes. Concentrations of all PEG solutions were $30 w / v \%$ and volumes were $100 \mu \mathrm{L}$. Fluorescence intensity is expressed as the 
percentage of the intensity of the untreated control cells. Columns represent the mean, \pm SEM, $\mathrm{n}=4$, after the highest and lowest values were excluded. Fluorescence intensity of the samples (mean \pm SEM): PEG 200: 268\% $\pm 10 \%$; PEG 300: 189\% $\pm 6 \%$; PEG 400: $144 \% \pm 21 \%$; PEG 600: 136\% $\pm 10 \%$; PEG 1000: $113 \% \pm 10 \%$; PEG 1500: 91\% $\pm 4 \%$; PEG 4000: $101 \% \pm 4 \%$; PEG 8000 : 115\% \pm 4\%; PEG 10,000: 146\% \pm 12\%; PEG 12,000: 132\% \pm 13\%; PEG 20,000: $117 \% \pm 6 \%$; Sorbitol $7 w / v \%: 118 \% \pm 4 \%$; Sorbitol $10 w / v \%: 135 \% \pm 5 \%$; Sorbitol $12.5 w / v \%: 185 \% \pm 8 \%$; and Sorbitol $35 \mathrm{w} / \mathrm{v} \%: 168 \% \pm 7 \%$.

\subsection{Flow Cytometry Results}

As sorbitol solutions had only limited impact on cells, we excluded them from further experiments. For flow cytometry, Caco-2 cells were stained with propidium iodide and labelled with annexin $\mathrm{V}$ to distinguish between necrotic and early apoptotic cells. Figure 5 shows the distribution of gated cells. The proportion of unstained, living cells (PI- AV -) increases with molecular weight. For low molecular weight PEGs, necrotic cells (PI+ AV+) are the dominant for dead cells and but with the increase in molecular weight the ratio of early apoptotic cells (PI- AV+) increases.

\section{Flow cytometry analysis of PEG treated Caco-2 cells}

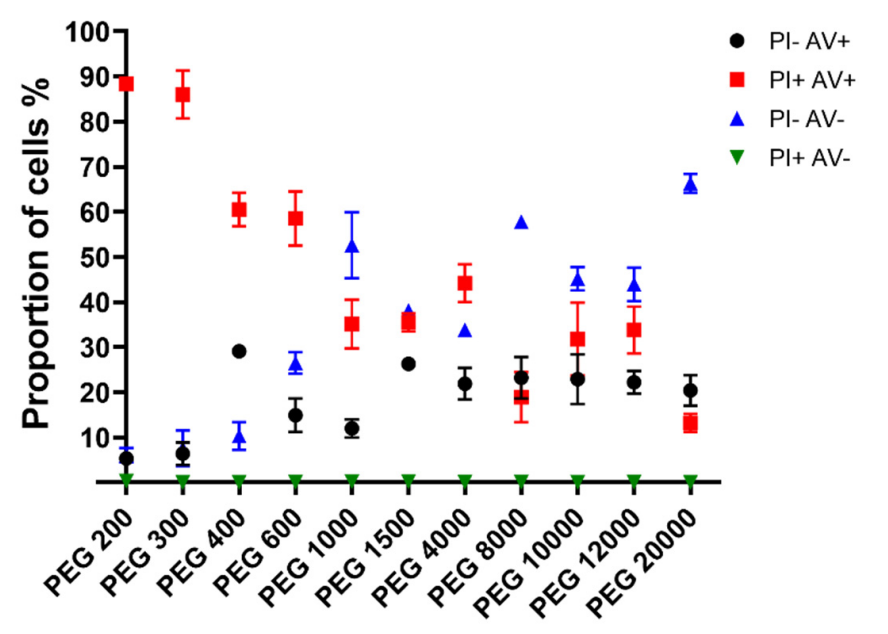

Figure 5. Proportion of living, dead, and apoptotic Caco-2 cells, measured by flow cytometry, treated with $1 \mathrm{~mL}$ of $30 \mathrm{w} / \mathrm{v} \%$ solutions of PEGs, stained with propidium iodide (PI) and annexin $\mathrm{V}(\mathrm{AV})$. Each point represents the mean of triplicates. Data represented as percentage distribution of cells between necrotic (PI+ AV+), early apoptotic (PI- AV+), living (PI- AV-), and incorrectly stained $(\mathrm{PI}+\mathrm{AV}-)$ populations of three independent experiments. Distribution of the samples as mean \pm SEM (PI- AV+; PI+ AV+; PI- AV-; and PI+ AV-): PEG 200: 5.3\% $\pm 1.3 \% ; 88.4 \% \pm 0.6 \%$; $6 \% \pm 1.6 \%$; and $0.3 \% \pm 0.3 \%$; PEG 300: $6.4 \% \pm 2.5 \% ; 86 \% \pm 5.3 \% ; 7.6 \% \pm 4 \%$; and $\pm 0 \% \pm 0 \%$; PEG 400: $29.1 \% \pm 0.6 \% ; 60.5 \% \pm 3.7 \%$; $10.3 \% \pm 3.1 \%$; and $\pm 0 \% \pm 0 \%$; PEG $600: 14.9 \% \pm 3.7 \% ; 58.5 \% \pm 6 \%$; $26.5 \% \pm 2.4 \%$; and $0.1 \% \pm 0.1 \%$; PEG 1000: $12 \% \pm 2 \% ; 35.1 \% \pm 5.4 \% ; 52.6 \% \pm 7.3 \%$; and $0.2 \% \pm 0.1 \%$; PEG 1500: $26.3 \% \pm 0.7 \% ; 35.5 \% \pm 2 \% ; 38.1 \% \pm 1.2 \%$; and $0.2 \% \pm 0.1 \%$; PEG $4000: 21.9 \% \pm 3.5 \%$; $44.2 \% \pm 4.2 \% ; 33.8 \% \pm 0.8 \%$; and $0.1 \% \pm 0 \%$; PEG $8000: 23.2 \% \pm 4.6 \% ; 18.9 \% \pm 5.6 \% ; 57.8 \% \pm 1.1 \%$; and $0.1 \% \pm 0.1 \%$; PEG 10,000: $22.9 \% \pm 5.5 \% ; 31.8 \% \pm 8.1 \% ; 45.2 \% \pm 2.6 \% ; 0 \% \pm 0 \%$; and PEG 12,000 : $22.2 \% \pm 2.5 \% ; 33.8 \% \pm 5.2 \% ; 43.9 \% \pm 3.7 \%$; and $0.1 \% \pm 0.1 \%$.

\subsection{In Vivo Toxicity Test}

G. mellonella larvae were injected with $20 \mu \mathrm{L}$ of the PEG solutions, their viability was checked four times during the two-day long experiment. The treated groups consisted of 10 healthy specimens. Figure 6 shows that mortality was significant for low molecular weight PEGs 200 and 300 (top) and medium molecular weight PEG 4000 (middle). No other PEG decreased survival of larvae significantly. 
Survival proportions of G. mellonella

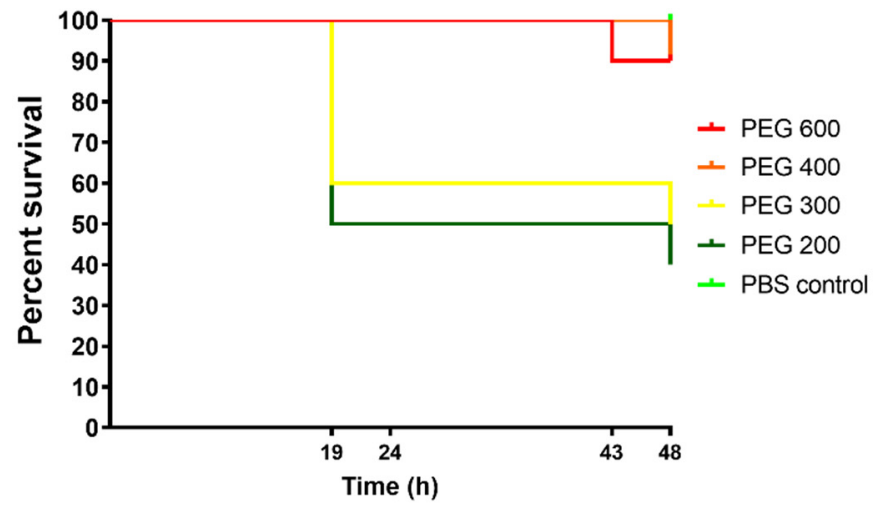

Survival proportions of G. mellonella

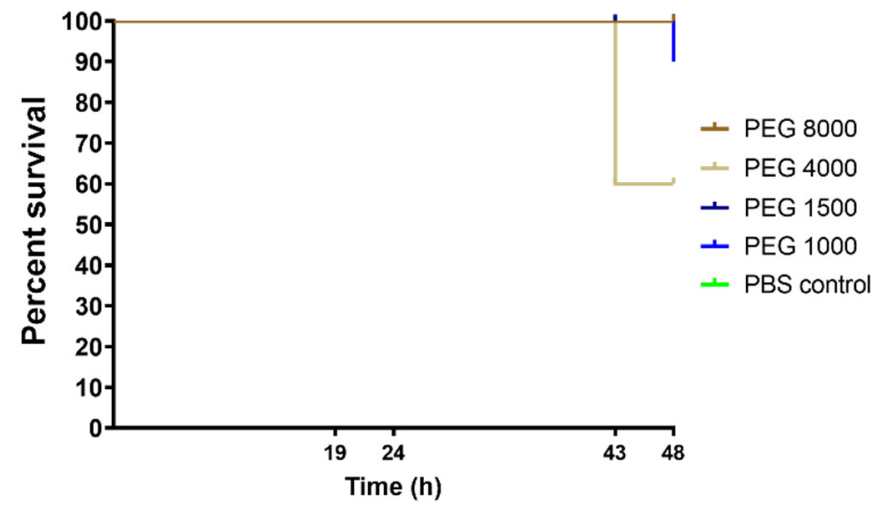

Survival proportions of G. mellonella

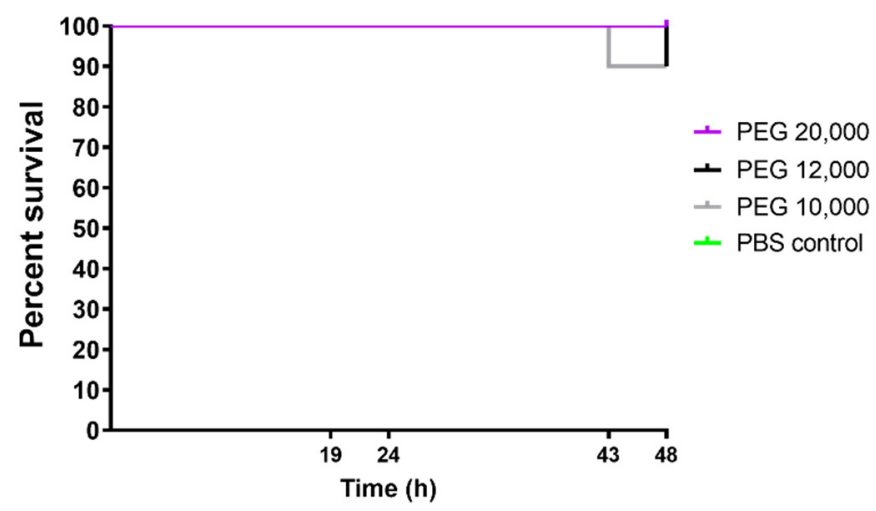

Figure 6. Kaplan-Meier survival curves of G. mellonella larvae. Each group consisted of 10 specimens, who were injected with $20 \mu \mathrm{L}$ of test samples. The following death events occurred during the experiment: 19 h: PEG 200: 5 (top), PEG 300: 4 (top); 43 h: PEG 600: 1 (top), PEG 4000: 4 (middle), PEG 10,000: 1 (bottom); 48 h: PEG 200: 1 (top), PEG 300: 1 (top), PEG 400: 1 (top), PEG 1000: 1 (middle) PEG 12,000: 1 (bottom). Significance of treated groups compared to PBS control according to Mantel-Cox log-rank test, and Gehan-Breslow-Wilcoxon test: PEG 200: ** /** (top); PEG 300: * /* (top); and PEG 4000: */* (middle); all others were insignificant.

\subsection{Correlation of Results with Molecular Weight}

As it can be seen in Table 1, we used Spearman correlation to find statistical relationship between the different measured data and the average molecular weight of PEGs. Osmolality, the proportion of necrotic cells (PI+ AV+ cells according to the flow cytometry) and total larvae mortality significantly decreases as molecular weight increases. The ratio of living cells according to both cytotoxicity assays and flow cytometry escalates as the PEGs average 
molecular weight increases. However, autophagy and the proportion of apoptotic cells had no statistical relationship with the chemical structure of PEGs.

Table 1. Correlation of measured data (only PEGs) with average molecular weight calculated by Spearman method. Significance levels are shown as: $\mathrm{ns}=p \geq 0.05 ;^{*}=p<0.05 ;{ }^{* *}=p<0.01$ and $* * *=p<0.001$.

\begin{tabular}{|c|c|c|}
\hline & Spearman Correlation Coefficient & Level of Significance \\
\hline Osmolality & -0.8091 & $* *$ \\
\hline Cell viability-MTT & 0.7909 & ** \\
\hline Cell viability-NR & 0.6241 & * \\
\hline Autophagy & ns & \\
\hline Proportion of $\mathrm{PI}-\mathrm{AV}+$ cells & ns & \\
\hline Proportion of $\mathrm{PI}-\mathrm{AV}+$ cells & -0.9273 & *** \\
\hline Proportion of $\mathrm{PI}-\mathrm{AV}-$ cells & 0.8455 & ** \\
\hline Total larvae mortality & -0.6357 & * \\
\hline
\end{tabular}

Additionally, the correlation matrix was calculated to compare the different data with each other, which is shown in Table 2. Autophagy had no statistical relationship overall. The other molecular weight independent cellular effect, the proportion of early apoptotic cells, had negative correlation with larvae mortality and a positive correlation with the NR assay. The different cell viability measurements (MTT, NR assays, and proportion of necrotic and living cells according to flow cytometry) had significant correlation with each other and with osmolality. The last data set, total larvae mortality, was only connected with flow cytometry results. Naturally, the most significant correlation could be found between the distribution of necrotic and living cells at flow cytometry.

Table 2. Correlation of matrix of all measured data sets (only PEGs). Spearman correlation coefficient and significance levels are shown as: $\mathrm{ns}=p \geq 0.05{ }^{*}=p<0.05 ;{ }^{* *}=p<0.01$; and ${ }^{* * * *}=p<0.0001$.

\begin{tabular}{|c|c|c|c|c|c|c|c|c|}
\hline & Osmolality & $\begin{array}{c}\text { Cell } \\
\text { Viability- } \\
\text { MTT }\end{array}$ & $\begin{array}{c}\text { Cell } \\
\text { Viability- } \\
\text { NR }\end{array}$ & Autophagy & $\begin{array}{c}\text { Proportion } \\
\text { of PI-AV+ } \\
\text { Cells }\end{array}$ & $\begin{array}{c}\text { Proportion } \\
\text { of PI+ AV+ } \\
\text { Cells }\end{array}$ & $\begin{array}{c}\text { Proportion } \\
\text { of PI-AV- } \\
\text { Cells }\end{array}$ & $\begin{array}{c}\text { Total } \\
\text { Larvae } \\
\text { Mortality }\end{array}$ \\
\hline Osmolality & - & $0.909 / * * * *$ & $-0.843 / * *$ & ns & ns & $0.755 / *$ & $-0.709 / *$ & ns \\
\hline Cell viability-MTT & $-0.909 / * * * *$ & - & $0.770 / * *$ & ns & ns & $-0.736 / *$ & $0.664 / *$ & ns \\
\hline Cell viability-NR & $-0.843 / * *$ & $0.770 / * *$ & - & ns & $0.620 / *$ & ns & ns & ns \\
\hline Autophagy & ns & ns & ns & - & ns & ns & ns & ns \\
\hline $\begin{array}{l}\text { Proportion of } \\
\text { PI-AV+ cells }\end{array}$ & ns & ns & $0.620 / *$ & ns & - & ns & ns & $-0.626 /^{*}$ \\
\hline $\begin{array}{c}\text { Proportion of PI+ } \\
\text { AV + cells }\end{array}$ & $0.755 /^{*}$ & $-0.736 /^{*}$ & ns & ns & ns & - & $-0.973 /^{* * * *}$ & $0.771 / * *$ \\
\hline $\begin{array}{l}\text { Proportion of } \\
\text { PI-AV-cells }\end{array}$ & $-0.709 /^{*}$ & $0.664 /^{*}$ & ns & ns & ns & $-0.973 / * * * *$ & - & $-0.771 / * *$ \\
\hline Larvae mortality & ns & ns & ns & ns & $-0.626 / *$ & $0.771 / * *$ & $-0.771 / * *$ & - \\
\hline
\end{tabular}

\section{Discussion}

Polyethylene glycols referred to as Macrogols in the European Pharmacopoeia [3], are one of the important excipients used in oral or parenteral dosage forms. Primarily, PEGs are clinically used as primary constipation treatment or to prepare for colonoscopy $[16,17]$. Due to their outstanding characteristics, such as chemical neutrality, hydrophilicity, high and moderate solubility in aqueous and organic solvents, respectively, and flexibility of backbone chain, these polymers are widely applied to improve pharmacological and biological properties of different pharmaceutical formulations [18]. PEGs are well-known for use in the development of stealth coating of nanoparticle surfaces which is based on the interaction between opsonins and the PEGylated surface $[19,20]$. As such, both physical properties and cellular effects of PEGs are important, yet most publications focus only on one given PEG and studies involving multiple derivatives are limited in number. We aimed to investigate their cellular effects on a wide scale of molecular weight and calculate correlation between the different measured properties. Previously, it was stated that simple 
biological effects such as cytotoxicity of PEGs are based on osmolality and can be predicted from molecular weight [21].

By first measuring osmolality and later investigating cytotoxicity, autophagy, necrotic/ apoptotic/living cell distribution, and in vivo toxicity, we tried to study multiple aspects of PEGs' biological effects. We used an OSMOMAT 070 osmometer for the measurement of osmolality of our solutions as vapor pressure method is appropriate for determination of osmolality or molecular weight [22-25]. In vitro cytotoxicity experiments were carried out on Caco-2 human colorectal adenocarcinoma cells as a general model cell line, but also as indicators of the susceptibility of the gastrointestinal tract as they morphologically represent the intestinal epithelium [26,27]. The cytotoxicity was assessed by MTT and Neutral Red assays which are widely used in vitro techniques. These methods complement each other as MTT detects cell viability based on an enzymatic conversion, while on the other hand, cellular uptake and incorporation of neutral red is measured. Due to the different mechanism of action, several publications applied both methods to investigate cytotoxicity of different chemicals [28-30]. In order to further study cytotoxic properties of PEGs, we used labelled annexin $\mathrm{V}$ and propidium iodide to discriminate between necrotic and early apoptotic cells with flow cytometry [29,31,32]. Autophagosome formation was measured by cellular organelle staining as a marker of autophagy, an inducible mechanism of cytotoxicity [33-35]. The different cytotoxic experiments were supplemented with the use of Galleria mellonella injection method. It is an emerging in vivo model organism for the determination of toxicity of various xenobiotics [36-38]. The method shows good correlation with cellular and other in vivo techniques in case of acute toxicity studies [39].

Regarding cytotoxicity, previously, few articles investigated the cytotoxic properties of PEGs on a wide scale of molecular weight. Liu et al. studied a series of PEG derivatives on the HeLa (human cervical cancer cells) and the L929 cell line (fibroblasts derived from mice) with MTT assay [40]. The involved PEG derivatives were TEG (triethylene glycol), PEG oligomers (PEG 400, PEG 1000, PEG 2000, and PEG 4000), and PEG-based monomers PEG methyl ether acrylate (mPEGA) and PEG methyl ether methacrylate (mPEGMA-500 and mPEGMA-950)). Their research showed that the PEG 400 and PEG 2000 were almost non-cytotoxic at a $5 \mathrm{mg} / \mathrm{mL}$ concentration. However, PEG 1000 and PEG 4000 were more toxic to cells, especially to the L929 cell line. This indicates that molecular weight and thus osmolality are not connected to cytotoxicity. Contrary to their report, we found that the cytotoxicity levels of PEG 400, PEG 1000, and PEG 4000 are ascending according to the MTT assay. The protocol of MTT assay is different between the two experiments, as we treated the cells with a much higher concentration of PEGs for a shorter period while Lie et al. incubated the cells for $24 \mathrm{~h}$. The latter highlights the influence of PEGs on the proliferation of the cells while our protocol was more focused on the acute effects. Additionally, Hodaei et al. reported that Caco-2 cells after $24 \mathrm{~h}$ of incubation of $4 \mathrm{w} / \mathrm{v} \%$ PEG 4000, PEG 6000, PEG 10,000, and PEG 35,000 no cytotoxic effect could be observed (cell viability: $100 \%, 96 \%, 92 \%$, and $88 \%$, respectively) while PEG 400 and PEG 15,000 at $4 w / v \%$ exhibited significant toxicity on cells (cell viability $45 \%$ and $48 \%$, respectively) as measured by MTT assay [12]. These results confirm that the acute, high concentration treatment has a significantly different pattern, than a long-term incubation as cell proliferation and cytotoxicity are not influenced in the same way by the presence of PEGs. Postic et al. investigated the effect of PEG 200, 2000, and 20,000, and poly(vinyl pyrrolidone) 8000 on membrane transport apoptotic markers, cell viability by PrestoBlue assay, cell morphology, and caspase $3 / 7$ activity on metastatic melanoma A375, mouse fibroblast 3T3, and human corneal epithelial cells [41]. After $72 \mathrm{~h}$ of incubation, higher concentrations of low molecular weight PEGs significantly changed the number and morphology of A375 cells compared to PVP 8000. Resazurin assay indicated that PEG 200 was more cytotoxic to A375 and 3T3 cells than the other PEGs, and PVP 8000 had a unique dose-dependent killing action against the cells. However, in the case of human corneal epithelial cells, all the three PEGs were significantly different from each other. Caspase $3 / 7$ activation showed time dependency and no correlation with molecular weight. Overall, it must be noted that the different 
cellular effects of PEGs were highly influenced by the incubation time and the type of cells as well.

Taken together, Spearman correlation showed (Table 1), that the average molecular weight of studied PEGs had significant positive correlation with cell viability according to MTT ( $p=0.0055)$ and NR assays $(p=0.0444)$ and the proportion of living cells according to flow cytometry $(p=0.0018)$. Additionally, a negative correlation was found between molecular weight and osmolality $(p=0.0039)$ and proportion of necrotic cells $(p=0.0001)$. This clearly means that low molecular weight PEGs have the highest cytotoxic activity, and this effect decreases with the increase in average PEG chain length. According to the correlation matrix, osmolality can be correlated with MTT $(p<0.0001)$, NR $(p=0.0018)$, proportion of living $(p=0.0182)$, and necrotic cells $(p=0.0098)$. These results further confirm that cytotoxicity of PEGs could be explained by the strong osmotic shock ( $30 w / v \%$ solutions of PEGs, incubation time: $30 \mathrm{~min}$ ) they inflict upon the cells. However, sorbitol solutions showed no cytotoxicity in the case of the MTT and NR assays, despite the fact that their osmolality was comparable to PEGs. We assume that osmolality alone cannot be responsible for the observed cell viability decrease and a not investigated factor or cellular effect, which is linked with molecular weight, must be responsible for the cytotoxicity of PEGs. Wang et al. reported that the mechanism of cellular uptake of PEGs was dependent on the molecular weight, as low molecular weight PEGs (750-2000) were taken up only by passive diffusion while, for longer derivatives, endocytosis was also an important mechanism [26]. Cellular uptake was also influenced by the time of incubation and temperature. Mesenchymal stem cells tolerated sodium chloride, sorbitol, and PEG 3000 in significantly different ways, although they were applied at the same osmolality [42]. The type of osmolyte influenced numerous investigated factors of chondrogenesis regardless of osmolality. As such, a possible explanation for our results is that only low molecular weight PEGs could enter the cells during the short incubation time and the specific sensitivity of Caco-2 cells towards PEGs and their tolerance towards sorbitol.Unfortunately, there are no publications regarding the effects of non-modified PEGs in G. mellonella larvae and on autophagosome formation, thus we cannot compare our results with previous publications. However, the relationship of osmotic stress and induction of autophagy is well studied and shows a strong influence [43,44]. Autophagosome formation had no correlation with molecular weight, which can be explained by recent findings, which indicate that generally, autophagy is a late phase response to osmotic stress [44]. The high autophagosome formation can be explained by the easy passage of low molecular weight PEGs into cells as it was reported, that even 30 min of hyperosmotic incubation can lead to formation of proteosomes [45]. Additionally, further investigation is required to determine which characteristic of PEGs is the most influential in the process. Surprising cellular effects of PEGs are not unheard of, as it was reported that PEG 35 can influence uptake of exosomes and reduce the levels of IL-1 $\beta$ [46]. Unmodified PEGs were previously not injected into G. mellonella for evaluation of toxicity, and we have found that only molecular weight $(p=0.0403)$ had significant correlation with total larvae mortality. Macromolecules are rarely tested in this new model organism, yet in high concentration they show concentration dependent toxicity [47]. Labelled annexin $\mathrm{V}$ was used as an indicator of early stage apoptosis, and we have found that the proportion of stained cells had no correlation with osmolality. The literature reports that linking PEG 12,000 to interferon- $\alpha 2 b$ did not significantly increase apoptotic activity, as well as PEG 5000 coated silver nanoparticles compared to citrated coated ones [48,49]. Further flow cytometry experiments are needed to describe how cells are divided between necrotic and early apoptotic population after PEG treatment, as we suspect that it is heavily influenced by PEG concentration and incubation time.

It can be concluded that osmolality and cell viability (measured by different methods) had significant correlation with molecular weight of PEGs, while the more complicated effects, such as early stage apoptosis, autophagosome formation, and larvae survival (in vivo toxicity) are not directly linked with molecular weight. When it is needed to predict biological effect of a previously untested PEG, only simple cellular interactions, 
such as (cyto)toxicity (through necrosis), can be estimated based on previous experiments with different molecular weight derivatives. Further studies are needed to reveal what properties of PEGs influence more complex mechanisms such as autophagosome formation or apoptosis. Through detailed testing, the responsible factors can be identified, and statistical correlations can be found to prove relations between biological effects and chemical or physical attributes. Until then, we suggest caution with estimation of cellular action of PEGs purely based upon molecular weight when a new derivative is compared to known ones.

\section{Conclusions}

In summary, various cellular effects, in vivo toxicity, and osmolality of eleven different polyethylene glycols were studied on Caco-2 cells. Statistical analysis of the various data sets found a significant correlation of cytotoxicity, osmolality, and molecular weight. Overall, low molecular weight PEGs exhibited significant decrease in cell viability and high osmolality and larvae mortality, while high molecular weight usually had limited effect on cells and decreased osmolality. Further scientific investigations should be undertaken to discover more about the effects of PEGs on autophagosome formation and early apoptosis, however it can be stated that certain biological action of PEGs cannot be estimated based on molecular weight.

Author Contributions: I.B., M.V., F.F. and D.N. designed the experiment. H.P.L.K., D.N., Á.R. and F.F. were responsible for carrying out the measurements. P.F., Z.U., F.F. and J.V., carried out the statistical analysis. I.B., M.V., F.F., Á.R. and D.N. evaluated the data. All authors have read and agreed to the published version of the manuscript.

Funding: The project was supported by the Stipendium Hungaricum Scholarship. The work was also supported by the GINOP-2.3.4-15-2020-00008 and the GINOP-2.3.3-15-2016-0002- “Developing Pharmaceutical Technology R \& D Infrastructure on the University of Debrecen" projects. The research was supported by the Thematic Excellence Programme (TKP2020-IKA-04) of the Ministry for Innovation and Technology in Hungary. The projects are co-financed by the European Union and the European Regional Development Fund.

Data Availability Statement: All data available upon request from the corresponding author.

Conflicts of Interest: The authors declare no conflict of interest.

\section{References}

1. Herzberger, J.; Kerstin, N.; Pohlit, H.; Seiwert, J.; Worm, M.; Frederik, R.; Wurm, H.F. Polymerization of ethylene oxide, propylene oxide, and other alkylene oxides: Synthesis, novel polymer architectures, and bioconjugation. Chem. Rev. 2016, 116, 2170-2243. [CrossRef] [PubMed]

2. Gullapalli, R.P.; Mazzitelli, C.L. Polyethylene Glycols in Oral and Parenteral Formulations-A Critical Review; Elsevier, B.V.: Amsterdam, The Netherlands, 2015; Volume 496, ISBN 9143164935.

3. D'souza, A.A.; Shegokar, R. Polyethylene glycol (PEG): A versatile polymer for pharmaceutical applications. Expert Opin. Drug Deliv. 2016, 13, 1257-1275. [CrossRef] [PubMed]

4. Yang, Z.; Peng, H.; Wang, W.; Liu, T. Crystallization behavior of poly( $\varepsilon$-caprolactone)/layered double hydroxide nanocomposites. J. Appl. Polym. Sci. 2010, 116, 2658-2667. [CrossRef]

5. Torsten, H. Polyethylene glycols (PEGs) and the pharmaceutical industry. Pharma Chem. 2002, 57-59.

6. Jang, H.J.; Shin, C.Y.; Kim, K.B. Safety evaluation of polyethylene glycol (PEG) compounds for cosmetic use. Toxicol. Res. 2015, 31, 105-136. [CrossRef] [PubMed]

7. Magdalena, K.; Potemski, P.; Drabczyk, A.; Kudłacik-kramarczyk, S.; Gł, M.; Grabowska, B.; Mierzwi, D. The Synthesis Methodology of PEGylated $\mathrm{Fe}_{3} \mathrm{O}_{4} @$ Ag Nanoparticles Supported by Their Physicochemical Evaluation. Molecules 2021, $26,1744$.

8. Salmaso, S.; Caliceti, P. Stealth properties to improve therapeutic efficacy of drug nanocarriers. J. Drug Deliv. 2013, $2013,1-19$. [CrossRef]

9. Herold, D.A.; Rodeheaver, G.T.; Bellamy, W.T.; Fitton, L.A.; Bruns, D.E.; Edlich, R.F. Toxicity of topical polyethylene glycol. Toxicol. Appl. Pharmacol. 1982, 65, 329-335. [CrossRef]

10. Prentice, D.E.; Majeed, S.K. Oral toxicity of polyethylene glycol (PEG 200) in monkeys and rats. Toxicol. Lett. 1978, 2, 119-122. [CrossRef]

11. Bruns, D.E.; Herold, D.A.; Rodeheaver, G.T.; Edlich, R.F. Polyethylene glycol intoxication in burn patients. Burns 1982, 9, 49-52. [CrossRef] 
12. Hodaei, D.; Baradaran, B.; Valizadeh, H.; Zakeri-Milani, P. Effects of polyethylene glycols on intestinal efflux pump expression and activity in Caco-2 cells. Braz. J. Pharm. Sci. 2015, 51, 745-754. [CrossRef]

13. Parnaud, G.; Corpet, D.E.; Gamet-Payrastre, L. Cytostatic effect of polyethylene glycol on human colonic adenocarcinoma cells. Int. J. Cancer 2001, 92, 63-69. [CrossRef]

14. Nemes, D.; Kovács, R.; Nagy, F.; Tóth, Z.; Herczegh, P.; Borbás, A.; Kelemen, V.; Pfliegler, W.P.; Rebenku, I.; Hajdu, P.B.; et al. Comparative biocompatibility and antimicrobial studies of sorbic acid derivates. Eur. J. Pharm. Sci. 2020, 143, 105162. [CrossRef]

15. Rusznyák, Á.; Malanga, M.; Fenyvesi, É.; Szente, L.; Váradi, J.; Bácskay, I.; Vecsernyés, M.; Vasvári, G.; Haimhoffer, Á.; Fehér, P.; et al. Investigation of the cellular effects of beta-cyclodextrin derivatives on Caco-2 intestinal epithelial cells. Pharmaceutics 2021, 13, 157. [CrossRef] [PubMed]

16. Pampati, V.; Fogel, R. Treatment options for primary constipation. Curr. Treat. Options Gastroenterol. 2004, 7, 225-233. [CrossRef] [PubMed]

17. Tran, L.C.; Di Palma, J.A. Lack of lasting effectiveness of PEG 3350 laxative treatment of constipation. J. Clin. Gastroenterol. 2005, 39, 600-602. [CrossRef] [PubMed]

18. Roberts, M.J.; Bentley, M.D.; Harris, J.M. Chemistry for peptide and protein PEGylation. Adv. Drug Deliv. Rev. 2012, 64, 116-127. [CrossRef]

19. Fam, S.Y.; Chee, C.F.; Yong, C.Y.; Ho, K.L.; Mariatulqabtiah, A.R.; Tan, W.S. Stealth coating of Nanoparticles in drug-delivery systems. Nanomaterials 2020, 10, 787. [CrossRef]

20. Li, S.D.; Huang, L. Nanoparticles evading the reticuloendothelial system: Role of the supported bilayer. Biochim. Biophys. Acta Biomembr. 2009, 1788, 2259-2266. [CrossRef]

21. Schiller, L.R.; Emmett, M.; Santa Ana, C.A.; Fordtran, J.S. Osmotic effects of polyethylene glycol. Gastroenterology 1988, 94, 933-941. [CrossRef]

22. Owens, D.E.; Peppas, N.A. Opsonization, biodistribution, and pharmacokinetics of polymeric nanoparticles. Int. J. Pharm. 2006, 307, 93-102. [CrossRef]

23. Gibson, D.J.; Yang, Q.; Kerekes, D.T.; Schultz, G.S. Medical honey and silver dressings do not interfere with each other's key functional attributes. Wounds 2014, 26, 309-316.

24. Misichronis, K.; Rangou, S.; Avgeropoulos, A. Synthesis and molecular and morphological characterization of poly(ptrimethylsilyl styrene) and diblock copolymers with poly(1,3- cyclohexadiene). Int. J. Polym. Anal. Charact. 2008, 13, 136-148. [CrossRef]

25. Marsano, E.; Bianchi, E.; Chimico-fisici, S.; Sintetiche, M.; Europa, C.; Chimica, D. Synthesis and characterization of block copolymers based on poly(p-benzamide) and poly(terephthalamide of p-aminobenzhydrazide). Polym. Commun. $1991,32,45$.

26. Wang, T.; Guo, Y.; He, Y.; Ren, T.; Yin, L.; Fawcett, J.P.; Gu, J.; Sun, H. Impact of molecular weight on the mechanism of cellular uptake of polyethylene glycols (PEGs) with particular reference to P-glycoprotein. Acta Pharm. Sin. B 2020, 10, $2002-2009$. [CrossRef] [PubMed]

27. De Matteis, V.; Rojas, M.; Cascione, M.; Mazzotta, S.; Di Sansebastiano, G.P.; Rinaldi, R. Physico-chemical properties of inorganic NPs influence the absorption rate of aquatic mosses reducing cytotoxicity on intestinal epithelial barrier model. Molecules 2021, 26, 2885. [CrossRef]

28. Florkiewicz, W.; Malina, D.; Pluta, K.; Rudnicka, K.; Gajewski, A.; Olejnik, E.; Tyliszczak, B.; Sobczak-Kupiec, A. Assessment of cytotoxicity and immune compatibility of phytochemicals-mediated biosynthesised silver nanoparticles using Cynara scolymus. IET Nanobiotechnol. 2019, 13, 726-735. [CrossRef]

29. George, B.P.A.; Tynga, I.M.; Abrahamse, H. In vitro antiproliferative effect of the acetone extract of rubus fairholmianus gard. Root on human colorectal cancer cells. Biomed. Res. Int. 2015, 2015, 165037.

30. Alam, F.; us Saqib, Q.N.; Waheed, A. Cytotoxic activity of extracts and crude saponins from Zanthoxylum armatum DC. against human breast (MCF-7, MDA-MB-468) and colorectal (Caco-2) cancer cell lines. BMC Complement. Altern. Med. 2017, 17, 368. [CrossRef] [PubMed]

31. Dino, P.; D’Anna, C.; Sangiorgi, C.; Di Sano, C.; Di Vincenzo, S.; Ferraro, M.; Pace, E. Cigarette smoke extract modulates E-Cadherin, Claudin-1 and miR-21 and promotes cancer invasiveness in human colorectal adenocarcinoma cells. Toxicol. Lett. 2019, 317, 102-109. [CrossRef] [PubMed]

32. Nozari, S.; Faridvand, Y.; Etesami, A.; Ahmad Khan Beiki, M.; Miresmaeili Mazrakhondi, S.A.; Abdolalizadeh, J. Potential anticancer effects of cell wall protein fractions from Lactobacillus paracasei on human intestinal Caco-2 cell line. Lett. Appl. Microbiol. 2019, 69, 148-154. [CrossRef]

33. Lauzier, A.; Normandeau-Guimond, J.; Vaillancourt-Lavigueur, V.; Boivin, V.; Charbonneau, M.; Rivard, N.; Scott, M.S.; Dubois, C.M.; Jean, S. Colorectal cancer cells respond differentially to autophagy inhibition in vivo. Sci. Rep. 2019, 9, 11316. [CrossRef] [PubMed]

34. Zhao, C.; Qiu, S.Z.; He, J.; Peng, Y.; Xu, H.; Feng, Z.; Huang, H.; Du, Y.; Zhou, Y.; Nie, Y. Prodigiosin impairs autophagosomelysosome fusion that sensitizes colorectal cancer cells to 5-fluorouracil-induced cell death. Cancer Lett. 2020, 481, 15-23. [CrossRef] [PubMed]

35. Akter, M.; Atique Ullah, A.K.M.; Banik, S.; Sikder, M.T.; Hosokawa, T.; Saito, T.; Kurasaki, M. Green Synthesized Silver Nanoparticles-Mediated Cytotoxic Effect in Colorectal Cancer Cells: NF-kB Signal Induced Apoptosis Through Autophagy. Biol. Trace Elem. Res. 2021, 199, 3272-3286. [CrossRef] 
36. Ignasiak, K.; Maxwell, A. Galleria mellonella (greater wax moth) larvae as a model for antibiotic susceptibility testing and acute toxicity trials. BMC Res. Notes 2017, 10, 428. [CrossRef]

37. Wijesinghe, G.K.; Maia, F.C.; de Oliveira, T.R.; de Feiria, S.N.B.; Joia, F.; Barbosa, J.P.; Boni, G.C.; de Cássia Orlandi Sardi, J.; Rosalen, P.L.; Höfling, J.F. Effect of cinnamomum verum leaf essential oil on virulence factors of candida species and determination of the in-vivo toxicity with galleria mellonella model. Mem. Inst. Oswaldo Cruz 2020, 115, 1-13. [CrossRef] [PubMed]

38. Moya-Andérico, L.; Vukomanovic, M.; del Mar Cendra, M.; Segura-Feliu, M.; Gil, V.; del Río, J.A.; Torrents, E. Utility of Galleria mellonella larvae for evaluating nanoparticle toxicology. Chemosphere 2021, 266, 129235. [CrossRef]

39. Allegra, E.; Titball, R.W.; Carter, J.; Champion, O.L. Galleria mellonella larvae allow the discrimination of toxic and non-toxic chemicals. Chemosphere 2018, 198, 469-472. [CrossRef]

40. Liu, G.; Li, Y.; Yang, L.; Wei, Y.; Wang, X.; Wang, Z.; Tao, L. Cytotoxicity study of polyethylene glycol derivatives. RSC Adv. 2017, 7, 18252-18259. [CrossRef]

41. Ivana Postic, H.S. Poly(ethylene glycol) induces cell toxicity in melanoma cells by producing a hyperosmotic extracellular medium. J. Biomater. Appl. 2018, 33, 693-706. [CrossRef]

42. Ahmadyan, S.; Kabiri, M.; Hanaee-Ahvaz, H.; Farazmand, A. Osmolyte Type and the Osmolarity Level Affect Chondrogenesis of Mesenchymal Stem Cells. Appl. Biochem. Biotechnol. 2018, 185, 507-523. [CrossRef]

43. Liu, Z.; Chen, D.; Chen, X.; Bian, F.; Gao, N.; Li, J.; Pflugfelder, S.C.; Li, D.Q. Autophagy activation protects ocular surface from inflammation in a dry eye model in vitro. Int. J. Mol. Sci. 2020, 21, 8966. [CrossRef]

44. Nunes, P.; Ernandez, T.; Roth, I.; Qiao, X.; Strebel, D.; Bouley, R.; Charollais, A.; Ramadori, P.; Foti, M.; Meda, P.; et al. Hypertonic stress promotes autophagy and microtubule-dependent autophagosomal clusters. Autophagy 2013, 9, 550-567. [CrossRef]

45. Yasuda, S.; Tsuchiya, H.; Kaiho, A.; Guo, Q.; Ikeuchi, K.; Endo, A.; Arai, N.; Ohtake, F.; Murata, S.; Inada, T.; et al. Stress- and ubiquitylation-dependent phase separation of the proteasome. Nature 2020, 578, 296-300. [CrossRef] [PubMed]

46. Closa, D.; Folch-puy, E. Polyethylene Glycol 35 (PEG35) Modulates Exosomal Uptake and Function. Polymers 2020, $12,3044$.

47. de Sousa, A.K.A.; Ribeiro, F.O.S.; de Oliveira, T.M.; de Araújo, A.R.; Dias, J.d.N.; Albuquerque, P.; Silva-Pereira, I.; de Jesus Oliveira, A.C.; Quelemes, P.V.; Leite, J.R.S.A.; et al. Quaternization of angico gum and evaluation of anti-staphylococcal effect and toxicity of their derivatives. Int. J. Biol. Macromol. 2020, 150, 1175-1183. [CrossRef]

48. Vyas, K.; Brassard, D.L.; DeLorenzo, M.M.; Sun, Y.; Grace, M.J.; Borden, E.C.; Leaman, D.W. Biologic activity of polyethylene glycol12000-Interferon- $\alpha 2 b$ Compared with Interferon- $\alpha 2 b$ : Gene Modulatory and Antigrowth Effects in Tumor Cells. J. Immunother. 2003, 26, 2489. [CrossRef] [PubMed]

49. Bastos, V.; Ferreira de Oliveira, J.M.P.; Brown, D.; Jonhston, H.; Malheiro, E.; Daniel-da-Silva, A.L.; Duarte, I.F.; Santos, C.; Oliveira, $\mathrm{H}$. The influence of Citrate or PEG coating on silver nanoparticle toxicity to a human keratinocyte cell line. Toxicol. Lett. 2016, 249, 29-41. [CrossRef] [PubMed] 